\title{
Safety Interlock Device
}

National Cancer Institute

\section{Source}

National Cancer Institute. Safety Interlock Device. NCI Thesaurus. Code C50154.

A mechanical or electronic device designed to prevent one action from happening when certain conditions exist. 